\title{
How South Korean Internet users experienced the impacts of the COVID-19 pandemic: discourse on Instagram
}

Seoyoung Kim (1) ${ }^{1}$, Hyun-Woo Lim (10 ${ }^{2 \otimes}$ \& Shin-Young Chung ${ }^{3}$

This study explores how South Korean individuals managed the impacts of the COVID-19 pandemic in their daily lives during a time of continuous and sustained social distancing using 8241 Instagram posts from May 6 to June 16, 2020. Co-word analysis found two main theme clusters highlighting individuals' endeavors in daily life management and their fear of COVID19 infection. DMR topic modeling analysis resulted in five higher-order themes, each reflecting different aspects of people's COVID-19 experiences. Overall, the results shed light on individuals' resilience in managing their daily lives despite the fear and discomfort caused by the pandemic. Results also highlight the possibility that the discursive practices of Social Network Services (SNS) reinforce hatred against social minorities and frame otherizing COVID-19 patients as legitimate. The present study suggests the need for a range of social support to help individuals and communities during the prolonged pandemic, including a long-term, large-scale psychological quarantine system. Deliberate social measures also need to be taken to promote the process of social sharing through media texts and SNS to resist hateful frames and othering of social minorities. Limitations of the study and suggestions for future research are provided.

\footnotetext{
${ }^{1}$ Yonsei University, Seoul, Republic of Korea. ${ }^{2}$ Hankuk University of Foreign Studies, Seoul, Republic of Korea. ${ }^{3}$ Korea Military Academy, Seoul, Republic of

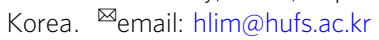




\section{Introduction}

o slow COVID-19 pandemic spread, governments across the globe have enacted ranges of social-distancing measures, including stay-at-home orders, travel restrictions, and closure of non-essential businesses (Hale et al., 2020). The rhetoric of "war against COVID-19" has been widely adopted in political and media discourse to communicate the severity of the crisis to the public and enforce restrictions (Maesse, 2020; Sohn, 2020). Home-based work, telemedicine, online religious services, and online-learning have also been branded as the "new normal", which is a disputed discursive construction, in social discourse across networked spaces. We expect that any new pandemic causes a broad array of anxiety and phobic disorders among the general public (Cheng and Tang, 2004; Lau et al., 2010; Ramalingaswami, 2001). Individuals could suffer from stress and helplessness caused by restrictions on going out of the home (LeeBaggley et al., 2004), economic losses including business layoffs, closures, and income loss (Mihashi et al., 2009), and other restrictions on normal activities (Main et al., 2011). Bisson et al. (2003) suggest that emotional distress and confusion could be a normal psychological reaction, rather than a pathological one, when people find information and coping resources insufficient to deal with a given social disaster. A recent review of studies on the impact of COVID-19 on mental health shows that the COVID-19 outbreak could cause fear, pervasive anxiety, frustration and boredom, and loneliness among the public (Serafini et al., 2020).

One useful concept for understanding how individuals cope with their psychological responses to a stress event is social sharing (Rimé et al., 1998). Studies on social sharing have shown that when individuals experience an emotional event, they talk with others about the event, their experienced feelings, and behavioral knowhows (Rimé, 2007, 2009). Through repeated circulations of a social sharing process, a community's shared emotional knowledge and responses to the event are continuously updated, transformed, and reconstructed. Such processes could help individuals reconstruct the meaning of a stress event and regulate their responses to it (Lepore et al., 2000; Nils and Rimé, 2012; Rimé, 2009) while strengthening the community's group identity and cohesion (Lawler, 2003; Nolen-Hoeksema and Davis, 1999; Páez et al., 2007). With the recent growth of Internet and mobile-based applications, Social Network Services (SNS) may serve as an important channel for spreading a community's shared knowledge. During the COVID-19 crisis, SNS platforms including Instagram, Facebook, and TikTok have seen a surge in use (Annapurani, 2020; Williamson, 2020). When people have kept physically distant from each other, they have turned to online networks as a major means of communication to stay connected with others and share their experiences (Nabity-Grover et al., 2020).

Scholars have drawn attention to the need to study the public discourse on social media and online content in recent decades (Bouvier and Machin, 2018; van Dijck, 2013). Our contemporaneous lives are no longer confined to an offline physical space but are instead brought into an online space. Online and offline spaces and the texts they produce are connected in complex ways; thus, we have become increasingly aware that at least some social actions in an offline space can be conditioned and even made possible by online infrastructures and algorithms (Blommaert and Maly, 2019; de Souza Júnior, 2021). However, the approaches to data collection, selection, and sampling employed by traditional discourse studies do not sometimes suit the particularities of studying the discourse of social media. The study of daily discourse practices of SNS users, for example, is often faced with large volumes of data dispersed throughout the platform (Dehghan et al., 2020), unlike many traditional discourse studies in which relatively small sizes of data were systematically selected and sampled to be representative of the discourse types and the focuses of the investigations. Thus, a study of social media discourse necessitates new methods for data collection and processing. To this end, recent studies have suggested the promise of applying text mining techniques for discourse analysis (Teso et al., 2018; Wiedemann, 2019). By combining discourse analysis and text mining, the current investigation aims to reveal public perceptions and experiences, as co-constructed through the process of SNS social sharing, about the pandemic and social distancing.

Discourse analysis in social media. Discourse analysis (DA) is an umbrella term encompassing different theoretical and methodological approaches to studying language. Some of the shared ideas include the view of discourse as a form of social practice, implying that discourse shapes social structures and relations as well as being shaped by them. In Fairclough and Wodak's (1997) explanation, discourse is constitutive in the sense that it helps to reproduce the existing social status quo as well as being able to transform it. Bearing this in mind, we define DA as the study of language use in its context and in the interaction among the speakers (van Dijk, 2008; Wodak, 2008).

The increase in social media use over the last decades around the world has allowed a wider variety of unfiltered ideas and opinions to be available in the online space (Gillmor, 2006). Khosravinik (2017) argues that social media has brought about a paradigm shift in communication. In SNS platforms, people are engaged in the interactional co-construction of knowledge and attitudes. As Cover (2012) rightly notes, the very use of SNS platforms is a performative act, and so writing a post about the pandemic and responding to it are performative acts by which people (re)construct their pandemic experiences and regulate their daily lives. Recent advancement in text mining techniques enables us to identify patterns and relations, which exist within a large body of language data, which otherwise would be difficult to interpret (Teso et al., 2018; Wiedemann, 2019).

Text mining method. Proposed by Feldman and Dagan (1995), natural language processing and text analyses can uncover topics hidden in unstructured text data, such as SNS postings (Janasik et al., 2009). Analysis of big data withdrawn from SNS has been spotlighted as a tool to examine social phenomena in many disciplines of social science (Boulianne, 2015). As an example, Brown et al. (2018) examined Instagram posts to analyze the severity and content of self-inflicted injuries.

Among text analytic methods, co-word analysis (Dam and Kaufmann, 2008) and Dirichlet Multinomial Regression topic modeling (DMR; Mimno and McCallum, 2008) are two of the most frequently used methods for interpreting social science data (e.g., Leech and Onwuebuzie, 2008). Co-word analysis is used to identify collaborative messages in text data based on high frequency co-occurring words. For example, if the words "anxiety" and "unemployment" were used frequently together in the data, this may suggest that people expressed anxiety in relation to unemployment. Other words paired with "anxiety" and "unemployment" can further reveal the severity and types of anxiety people experienced in relation to unemployment. By contrast, topic modeling programmatically extracts salient latent topics to constitute the data through random-sampling iterations. The topic modeling with DMR method additionally allows researchers to incorporate arbitrary document features (hereafter, metadata), such as the names of publishers, publication dates, and venues, so the results can be interpreted with contextual information. 
The overarching objective that guides the current study is identification of emotional and behavioral responses expressed by South Korean people in relation to the pandemic and social distancing. To do this, we retrieved a large collection of Instagram posts and text analyzed the data, utilizing co-word and DMR topic modeling analyses. We chose Instagram posts since more than half of Korean SNS users between 18- and 24-years old access Instagram multiple times a day (Kim, 2019). Instagram could reach a large volume of users. In addition, users' frequent and immediate access to it renders the Instagram posts to be "real-time" discourse, being constantly co-constructed (and deconstructed) by individuals in the process of adapting to their daily lives. Especially during a time of social distancing, Instagram posts could become a more important site of discursive practices to negotiate change.

The time period of analysis was from May 6, 2020 to June 16, 2020. During this period, the South Korean government eased the intense prevention measures (e.g. containment, intense social distancing) to "everyday-life quarantine," as sustained socialdistancing measures (Korean Central Disease Control Headquarters, 2020). In the beginning period of the pandemic, the rapid regional spread and increase of patient numbers up to 320 people per day in metropolitan areas by February 19, 2020 induced the Korean government to urgently implement intense social-distancing measures from March 1, 2020 through May 5, 2020 (Korean Central Disease Control Headquarters, 2020). In response to the order and its cause, collaborative efforts by Koreans have reduced the spread and induced the easing of Korean virus policy to the everyday-life quarantine level (Martin and Yoon, 2020; Oh, 2020).

Considering the data of daily Instagram posts produced during a time of sustained social distancing, we had the following questions in mind in the process of data analysis and discussion: What messages were being co-constructed by South Korean Instagram users in the process of negotiating the change during the COVID-19 crisis? What (or whose) voices were heard strongly and what were suppressed during the processes of meaning-making and (re)interpretation?

\section{Methods}

Data collection and pre-processing of text. The data used in the present study were Instagram posts during the period of everyday-life quarantine in Korea (May 6, 2020-June 16, 2020). The posts were collected with hashtag queries by either or both "\#social_distancing" or/and "\#everyday_distancing" (in Korean language) using a computerized crawler written on Python 3.6. The information crawled included the dates of posts, main text bodies, and descriptions of posted images, but no uninterpretable unicodes like emoticons (mean number of crawled posts per day $=651.48$ ). No personal information regarding the account holders (e.g., username, posted location) was crawled. The resulting number of posts was 27,362.

The initial data pool was further screened using the following exclusion criteria: (1) regrammed (i.e., reposted) posts; (2) posts that did not contain the terms, "Corona" and/or "COVID" in the main text bodies. The final data set comprised 8241 posts. They were then qualitatively scrutinized and sorted into three subsets depending upon the aim of the post contents: (1) "ANN" for posts that delivered official announcement/news from (local) government or press $(n=287)$; (2) "BIZ" for posts that aimed to sell merchandise (e.g., masks) or promote commercial campaigns $(n=2799)$; and (3) "Everyday-Life" for posts that conveyed individuals' everyday experiences and emotions in relation to COVID-19 and social distancing $(n=5155)$.

Unstructured text data, such as Instagram posts used in this study, requires rigorous pre-processing prior to main analyses
(Dutt, 2015), as posts often miss spacing and contain spelling errors, which potentially pose a threat to the consistency of analytic procedures and the credibility of results. The initial step in the pre-processing involved tokenization, by which the main text bodies and descriptions of the posted images were systematically chunked into individual sentences, and further into unigram words/tokens (Manning et al., 2014). The Korean Morphological Analyzer (KOMORAN, https://github.com/ shineware/KOMORAN) was used to pull out the meaningful tokens and filter out stop words. Stop words are words or word elements that are considered to contribute little to semantic analysis being investigated and should be filtered out before analyzing the data. We listed a set of Korean stop words that would add little to our discussion (see https://www.ranks.nl/ stopwords/korean) and removed them from the data.

Co-word analysis. Co-word analyses were conducted for each data subset (ANN, BIZ, and Everyday-Life). We calculated a bigram (token-to-token) co-word matrix based on the frequency distribution of two tokens used adjacently together in the same sentence and then created a graph network with nodes and edges, using Gephi graph visualization software (https://gephi.org/). The nodes represent tokens, and edges convey information about the links between the nodes. To obtain a more interpretable co-word network, we set a threshold of co-occurring frequency to each data subset; following previous studies (e.g., Bruns, 2012) in which when visualizing large-scale text data, the threshold value was decided according to the number of nodes the researcher deemed adequate to display in one network. For the EverydayLife data, the set threshold value was 69. Its co-word network consisting of 70 times or more co-occurring token pairs included 247 nodes (2.54\% of nodes before threshold) and 1014 edges ( $0.24 \%$ of the entire links). The nodes were translated into English for the purpose of presentation.

DMR topic modeling analysis. To identify the topics emerging from the Instagram posts in relation to COVID-19 and social distancing, DMR topic modeling was conducted for the Everyday-Life data, using Machine Learning for Language Toolkit (MALLET; McCallum, 2002). MALLET is a Java-based package for text analysis, which provides efficient routines for transforming text documents into numerical representations to make probabilistic inferences such as Bayesian inference used in DMR (Mimno and McCallum, 2008). In our study, the posted dates were entered as metadata during the model estimation (Mimno and McCallum, 2008; the number of random token sampling iteration $=2000$ ). By incorporating a nominal variable like posted dates, we could draw inferences in relation to the metadata, such as daily topic distribution changes. The ANN and BIZ data sets were not put to topic modeling because the data sizes were smaller than are conventionally recommended for an extended method like DMR (e.g., 1,737,969 tweets used in Bae et al., 2013). To generate a parsimonious topic model with the most coverage, we compared multiple models with 10 to 15 topics for interpretability, with consideration of degrees of perplexity (Blei et al., 2003) as a quantifiable measure for how well a model fits the input data. The iterative reviews of the tokens and their contexts resulted in a model comprising 13 topics, which were further categorized into five higher-order themes based on between-topic thematic commonalities in order to interpret the differences and relationships among the themes.

Our presentation of results focuses on those from the Everyday-Life data, with the results from the other two data sets being used as a reference to interpret South Korean Instagram users' responses to the COVID-19 crisis. 


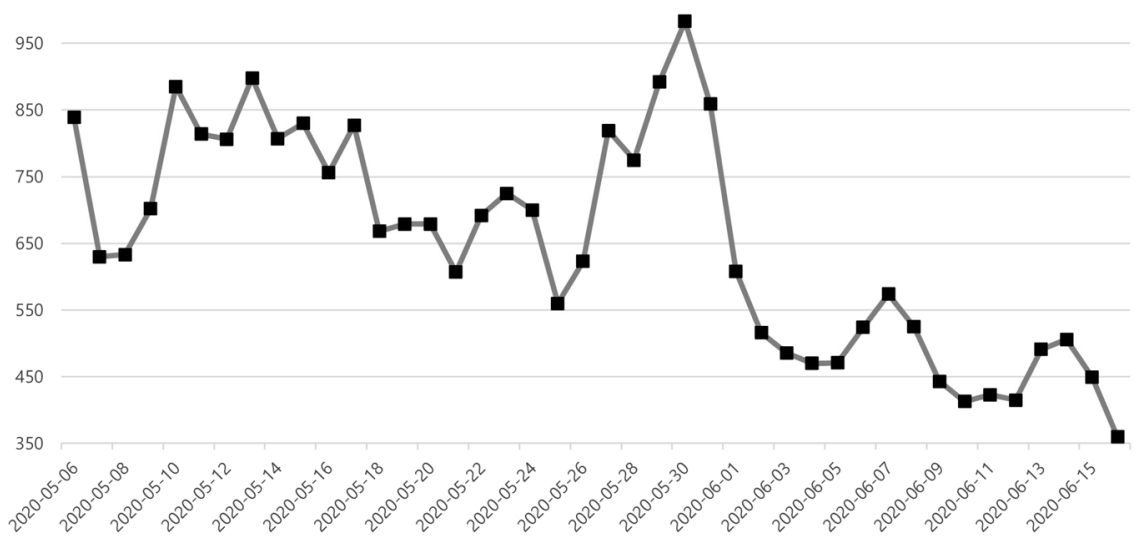

Fig. 1 Distribution of daily Instagram posts during the sustained social-distancing period. The $y$-axis indicates the number of Instagram posts and the $x$ axis indicates the posted dates.

\begin{tabular}{|c|c|c|c|c|c|}
\hline \multicolumn{2}{|c|}{ ANN $(n=287)$} & \multicolumn{2}{|c|}{$\mathrm{BIZ}(n=2799)$} & \multicolumn{2}{|c|}{$\begin{array}{l}\text { Everyday-life } \\
(n=5155)\end{array}$} \\
\hline Descriptor & Freq. & Descriptor & Freq. & Descriptor & Freq. \\
\hline Outdoor & 26 & Outdoor & 373 & Outdoor & 1382 \\
\hline Indoor & 13 & Nature & 212 & Sky & 611 \\
\hline Tree & 5 & Indoor & 178 & Nature & 564 \\
\hline Table & 4 & Food & 116 & Indoor & 489 \\
\hline Sky & 4 & Sky & 114 & Food & 484 \\
\hline Nature & 4 & Plant & 107 & Tree & 433 \\
\hline Plant & 3 & Tree & 89 & Plant & 356 \\
\hline Drink & 2 & Flower & 63 & Cloud & 205 \\
\hline Playing & 2 & Shoes & 54 & Child & 177 \\
\hline Child & 2 & Table & 45 & Water & 165 \\
\hline
\end{tabular}

Freq The frequency of each descriptor. The descriptors that well discriminate the different images are shown in bold.

\section{Results and discussion}

Daily distribution of Instagram posts and image descriptions. The number of posts during the data collection period (May 6, 2020-June 16, 2020), as presented in Fig. 1, exhibits rising and falling frequency, with two distinctive spikes on May 10 to 13 (post $n=3403$ ), and May 28 to 30 (post $n=2650$ ). The first of the distinctive increases in daily posts coincided with the point when the daily number of new patients increased and the infection spread out, starting from a nightclub in Itaewon, Seoul (Kim, $2020 \mathrm{~b}$ ). The next significant rise occurred when the daily number of new patients increased again, with a group of couriers from a large delivery company being found to be infected (Shim et al., 2020). The infection of couriers sparked concern, possibly because people had increasingly relied upon online orders and delivery to follow social-distancing guidelines. Figure 1 shows that the number of daily posts decreased after May 30, when the daily number of new patients dropped under 30 (Kang, 2020). Overall, the rising and falling curve in the number of daily posts appears to reflect an increase and decrease in people's effort to regulate their fear and anxiety; the more they felt fearful and anxious due to the threat of infection, the more often they were likely to express it in Instagram posts.

Table 1 presents the ten most frequent descriptors of the Instagram photos in each of the three data sets. Across the three data sets, the topmost frequent descriptor was "outdoor," along with descriptors for natural environments (e.g., tree, nature, and sky); the second most frequent one was "indoor," accompanied by eating-related descriptors (e.g., food, drink, and table). This may show that the two primary interests for people during the period pertained to "going out into a natural environment" and "eating indoors". In South Korea, the month of May is a time for people to enjoy family and social gatherings because there are multiple holidays such as Children's Day and Parents' Day. Some families traveled near (i.e., outdoors) while others chose to dine at home with their family members (i.e., indoors), rather than eat out (Jang, 2020). With the sustained social-distancing measures, local governments reopened public facilities including parks, museums, and libraries (Lee, 2020b), encouraging people to return to their daily lives while adhering to newly administered public regulations such as signing in before entering public facilities. Aside from outdoor and indoor related descriptors, "child" was included among the ten most frequent descriptors both in ANN and Everyday-Life data sets. This reflects the fact that families, as well as governments, were greatly concerned about child-rearing and education as students had not been able to attend school for quite some time (Nam, 2020).

Co-word network. The network of thematic relationships among the co-occurring words emerging from the Everyday-Life data is presented in Fig. 2. It shows that the co-word network comprises two main clusters, or naturally formed families of nodes. The purple-colored cluster, or Cluster 1, is formed around the master nodes of "COVID-19," "Social," "Distance," and "Mask," and contains the secondary nodes of "Daily life," "Today," "Living," and "Thoughts."

Table 2 summarizes the tokens constituting Cluster 1 along with their categories and frequencies. As shown in Table 2, the tokens linked to the main nodes of Cluster 1 pertain to individuals' daily life management amid COVID-19. Overall, they show that people were striving to maintain (or recover) their normal lives and positive emotional states while they worried about COVID-19 and exerted to overcome it. Specifically, the most frequent co-occurring words were related to maintaining their normal routines (work out, play, and going to school: e.g., "[I] started working out again"), staying connected with others (communication: e.g., "We held a neighborhood gathering"), and following safety measures (putting into action, and overcome: e.g., "Let's keep up with COVID-19 prevention rules for all of us"). People also worried about their families - particularly about their children (parenting, working mom: e.g., "Schools have started to open for two days a week and finally I could breathe a little; yet my kids and I still feel trapped and tired"). They further expressed their compassion for suffering neighbors such as friends, medical staff, and other human beings. Notably, the 

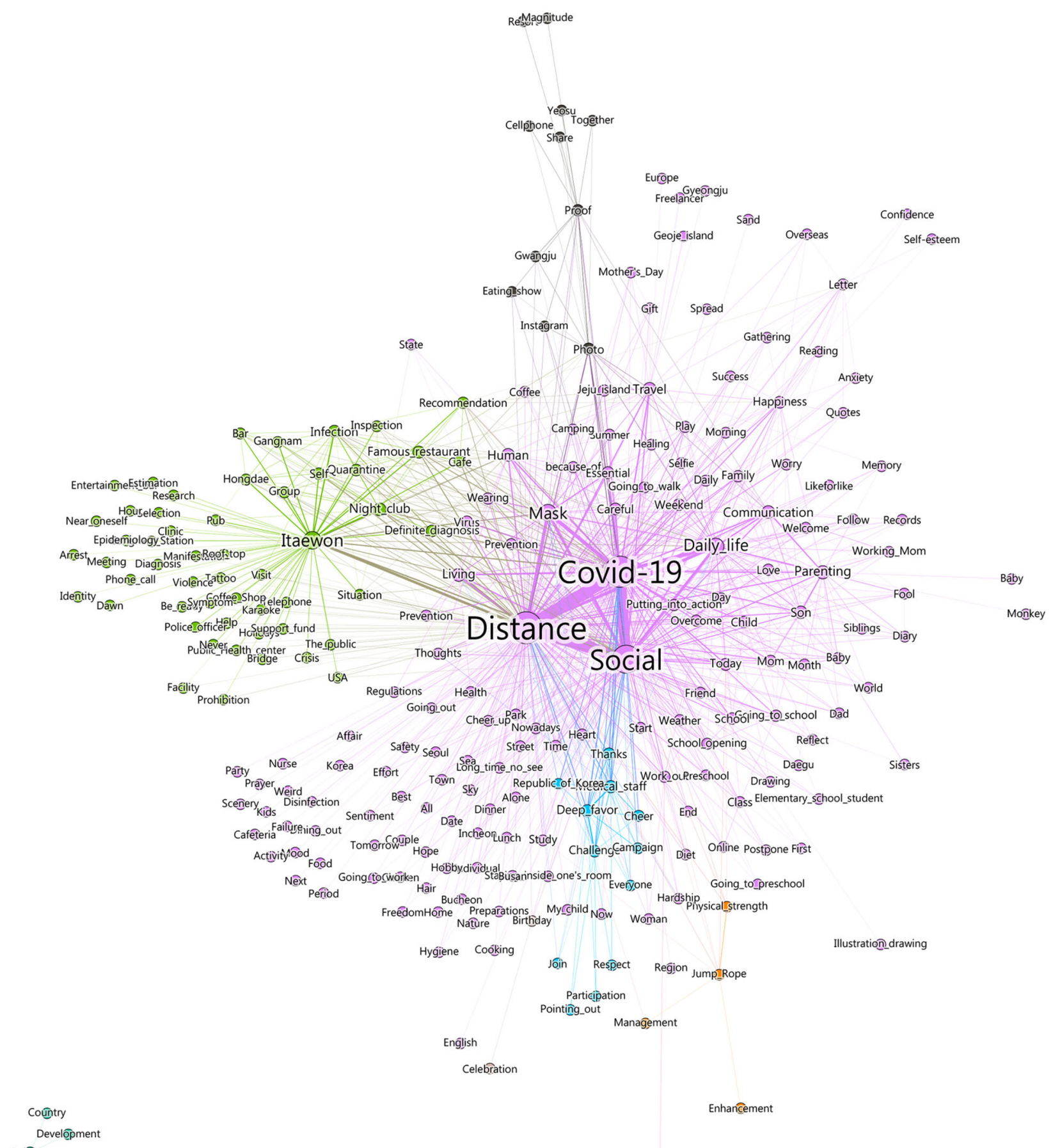

Enhançement

Balạnce

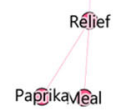

Fig. 2 Co-word network of Instagram posts regarding COVID-19 and social distancing. The size of nodes $(n=247)$ is automatically adjusted by the importance of each node (i.e., token frequency) relatively to other nodes, and the thickness of edges $(n=1014)$ reflects the strength of the paired nodes' links (i.e., co-occurring frequency), using Force Atlas layout to illuminate the difference in importance/strength. Modularity centrality was used to apply different colors to clusters.

emotions addressed in the posts were positive ones such as happiness and gratitude, rather than negative ones. One reason for this may be that people can pursue positive emotion in an effort to reappraise a difficult situation (Alhabash and Ma, 2017). In addition, tokens belonging to the time and location were related to the fact that there were multiple holidays and familygatherings in May (weekend, famous restaurant: e.g.,
“\#Parents_Day [...] my entire family dined out for the first time since COVID-19”).

The green-colored cluster, or Cluster 2, is formed around the node "Itaewon" (an area where the COVID-19 outbreak occurred around May 10, 2020; also refer to Fig. 1), branched out from the master nodes of "social" and "distance". Overall, Cluster 2 reflects people's fear of COVID-19 spread. It contains the nodes referring 
Table 2 Tokens associated with the main nodes of Cluster 1.

\section{Cluster 1 (main nodes: daily life; today)}

\begin{tabular}{ll}
\hline Category & Associated tokens \\
\hline Activity and event & $\begin{array}{l}\text { Communication; travel; document; work out; going to walk; putting into action; overcome; play; going to school; } \\
\text { jump rope; school opening; painting }\end{array}$ \\
Family & Parenting; child-rearing; son; family; mother; working mom; baby; child; sibling \\
Emotional expression & Happiness; essential; careful; love; welcome; deep favor; healing; heart; gratitude \\
Time and location & Weekend; famous restaurant; café; school; time; summer \\
COVID-19 specific & Mask; virus \\
Other people & Human (people); friend; medical staff; world; elementary student \\
Health & Health; physical strength \\
Else & Photo; diary; selfie; weather; memory; a new beginning; coffee; recommendation; etc.
\end{tabular}

Frequency indicates the sum of associated tokens' co-occurring frequencies to the main nodes. Associated tokens are presented in order of co-occurring frequency, from highest to lowest. Categories are named for each set of tokens based on between-token thematic commonalities.

Table 3 Tokens associated with the main nodes of Cluster 2.

\section{Cluster 2 (main nodes: Itaewon; nightclub; Gangnam; Hongdae)}

\begin{tabular}{|c|c|c|}
\hline Category & Associated tokens & Frequency \\
\hline $\begin{array}{l}\text { COVID-19 prevention measures and } \\
\text { damage control }\end{array}$ & $\begin{array}{l}\text { Quarantine; group; definite diagnosis; test; visit; support fund; public/community health center; } \\
\text { investigation; screening; clinic; estimation; epidemiology; disinfection; gathering; prohibition; } \\
\text { facility; identity }\end{array}$ & 6393 \\
\hline Time and location & $\begin{array}{l}\text { One's own home; today; famous restaurant; bar; café; pub; karaoke; coffee shop; rooftop; holiday; } \\
\text { USA; entertainment bar }\end{array}$ & 4694 \\
\hline COVID-19 specific & Infection; mask; virus; symptoms; state; situation & 3910 \\
\hline General reactions & Living; daily life; crisis; should never; help; preparation; thoughts; happiness & 1837 \\
\hline Other people & Human (people); the general public; police & 927 \\
\hline Else & Recommendation; phone call; tattoo; assault; arrest; etc. & 1359 \\
\hline
\end{tabular}

to specific locations and places known for young people to gather and play. Among the frequently mentioned locations and places were "nightclub" $(n=1070)$, followed by "Gangnam (station)" $(n=674)$, "Hongdae" (a downtown around a major private university; $n=578)$, "famous restaurant" $(n=576)$, and other types of places for eating and playing [e.g., bar, café/coffee shop, pub, and karaoke (altogether $n=1630$ )].

Table 3 summarizes the tokens constituting Cluster 2 along with their categories and frequencies. As shown in Table 3, tokens linked to the main nodes of Cluster 2 reflect the impact of the COVID-19 spread from a nightclub in Itaewon.

The most frequent tokens co-occurring with the main nodes are those belonging to the category of COVID-19 prevention measures and damage control. News updates from the epidemiological investigations on the mass infection raised public fear (e.g., "I've been anxious recently, and here comes another report of newly diagnosed COVID-19 patients in the neighborhood"). "Identity" within this category is related to the fact that the nightclub was known as a place for LGBTQ persons. In addition, the tokens in the time and location category are those referring to entertainment venues such as bars, pubs, karaoke, and coffee shops (e.g., "[P]lease keep in mind that medical staff and the many people searching for a job are having a very hard time because of some thoughtless, pleasure-seeking people"). This indicates that people deemed these places to be responsible for the COVID-19 spread and be a threat to their livelihoods.

Topic model. Table 4 presents the topic model for the EverydayLife data comprising five higher-order themes encompassing 13 topics. The themes are: (a) Self-care strategies; (b) Fears of
COVID-19's re-proliferation and worries about children's education; (c) Recognition of external support; (d) Recuperation from the intense social distancing; and (e) Daily life management during the sustained social-distancing period. The self-care strategies that Korean individuals addressed in relation to COVID-19 situations (Theme 1) included three topics - adhering to COVID19 prevention guidelines (e.g., washing hands), protecting psychological stability (e.g., self-esteem, confidence), and maintaining physical health (e.g., diet, power walk).

In Theme 2, the fear of COVID-19's re-proliferation, triggered by new patients occurring at the Itaewon nightclub, was accompanied by worries about their children not being able to attend school as well as blame for those believed responsible for re-proliferation of COVID-19. Particularly, in relation to the Itaewon nightclub patient, the accusation of LGBTQ people for posing a threat to the community was one prominent message. Some people blatantly blamed LGBTQ people for irresponsibility and failure to follow the safety measures (e.g., "I wish they [i.e., Itaewon club patients] were not provided with national medical assistance").

LGBTQ people have been subjected to the most severe discrimination among the social minority groups in South Korean society (Kim, 2004). South Korea's intolerance toward LGBTQ persons has often been attributed to the influence of Confucian values, which emphasize the importance of continuing the family line and prioritize group harmony over an individual's freedom (Rich and Eliassen, 2019). When an LGBTQ person received a lot of attention in the news for contracting COVID-19, this episode was followed by a large volume of social media mentions. Through these, those people have been framed as 
Table 4 Topic model for Instagram posts during the sustained social-distancing period.

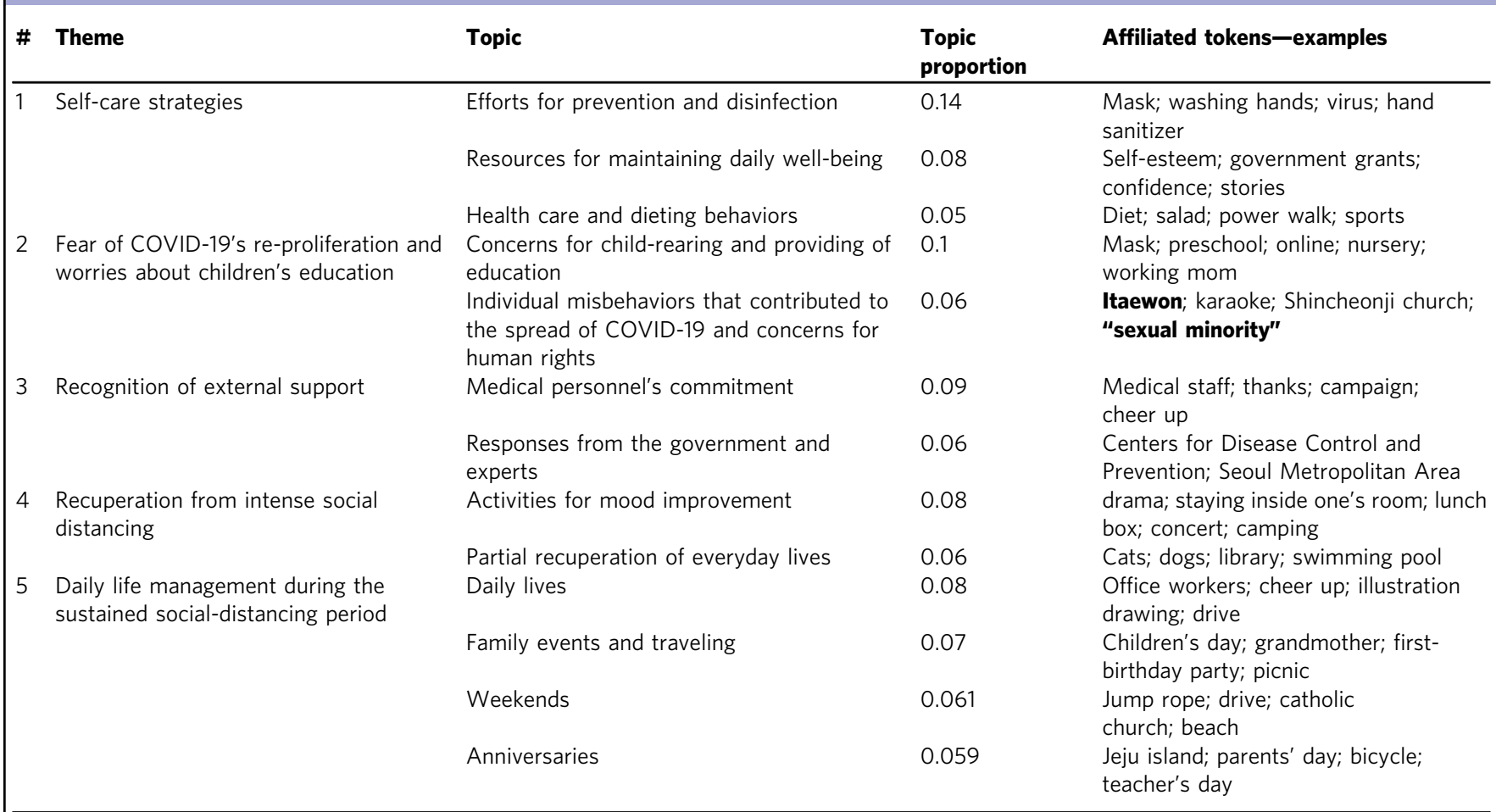

Topic proportion indicates the relative importance among the affiliated tokens, accounting for the entirety of Everyday-Life data. The tokens of importance for theme interpretation are shown in bold.

"unhealthy", "reckless", and "wrong" individuals. That episode also contributed to implicating LGBTQ citizens in the dissemination of the virus, as a probable catalyst for its spread. In addition to the existing intolerance and hatred against LGBTQ people, such media reports seemed to fuel public fear and frustration. In our data, Theme 2 suggests that the hate frame against LGBTQ people was being reproduced and circulated through Instagram posts. Yet there were voices that worried about human rights violations (e.g., "[I]ndiscreet disclosure of patient identities could kill some of them.") and possible negative impact on reducing the virus spread (e.g., "It would force gay people to be reluctant to take the COVID-19 test even when they have COVID-19 suspected symptoms").

Theme 3 shows that people appreciated commitment and support from medical personnel, the KDCA, and local governments (e.g., "I feel deeply thankful to medical staffs and public officials' hard work"). Theme 4 reflects people's relaxed mood after social-distancing measures were eased to everyday quarantine. With local museums and libraries re-opening, people started to step outside and shared the resources they could use for self-care and leisure, such as online concerts, and rebuilding their lifestyles sustainably through the ongoing COVID-19 pandemic (e.g., "Today, my daughter and I went to Song-Eun Art Space. The COVID-19 has changed my daughter's life a lot"). Lastly, Theme 5 pertains to individuals' daily life management, including spending time with family members on anniversaries and holidays, and going on weekend trips while maintaining socialdistancing guidelines (e.g., "Despite the continued social distancing, we went out for a walk away from the neighborhood").

Figure 3 shows the changes over time in the topic proportion estimates of Theme 1 (self-care strategies) and Theme 2 (fear of COVID-19's re-proliferation and worries about children's education). Seemingly, the line pattern for Theme 1 follows behind in time the pattern of the line for Theme 2 . This may indicate that increased fear overwhelms people, pushing them to focus primarily on regulating their emotions; once the fear is reduced to a manageable level, people start to express their increased concern about self-care strategies as a reaction to the experienced fear.

Figure 4 represents the changes over time in the topic proportion estimates of Theme 2 and Theme 3 (recognition of external support). As discussed earlier in relation to Fig. 1, it also shows that people expressed their fear and worries relating to COVID-19's re-proliferation the most around May 10-13 (nightclub case). What is interesting about Fig. 4 is that while in the earlier period (May 06-26), people's recognition of external support (e.g., health service) tends to move along with their fear of COVID-19 re-proliferation, in the later period (May 27- June 16) the two themes seem to move separately from each other. In other words, in the later period, despite increased fear and worries, people did not rely much on support from the authorities, such as medical experts, KDCA, and governments. Instead, people seemed to become more concerned with recuperating and rebuilding their daily lives while employing self-care strategies to prevent COVID-19 transmission.

Figure 5 elaborates on the interpretation by adding average proportions of Themes 1, 4, and 5 (self-care strategies, recuperation from intense social distancing, and daily life management), which together can explain South Korean people's interest in rebuilding lives despite COVID-19. In the later period of social distancing, when the fearful reactions increased, discussions centered on the means and ideas for rebuilding daily lives were stimulated; on the other hand, the recognition of external support stayed relatively independent of the fearful reactions and became less enthusiastic in its volume of reference compared to how it was during the early phase of social distancing (before May 27). One possible explanation is that as the pandemic continued, the interventions and support provided 


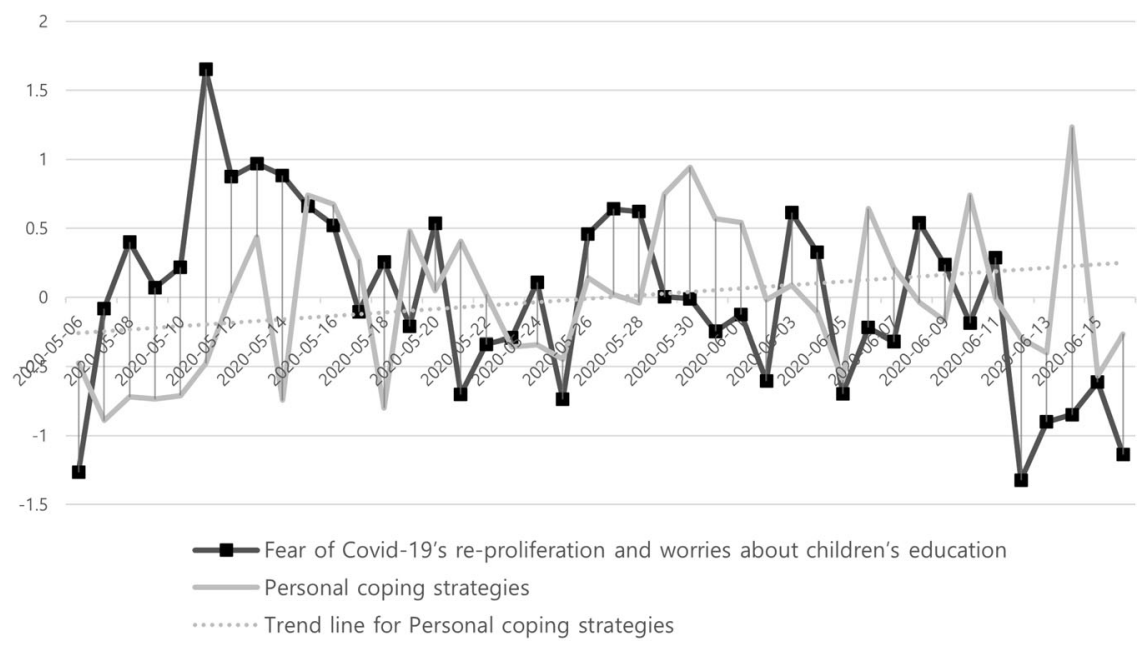

Fig. 3 Topic proportions of Fear of COVID-19 Re-Proliferation and Self-Care Strategies. The $y$-axis indicates the average topic proportion estimates per theme, and the $x$-axis indicates the posted dates.

by governments and health agencies, which were effective for regulating fearful emotions during the initial stage of the pandemic, might no longer be useful for recuperating and managing their daily lives. They seemed to resort to other resources such as being close to family (e.g., "grandmother", "parent's day"), engaging in personal hobbies (e.g., "drama", "concert", "camping"), being committed to daily life tasks (e.g., "office worker", "cheer up", "drive"), etc.

\section{Overall discussion}

Analyses of the Instagram posts by South Koreans in relation to COVID-19 and social distancing reveal dynamics between individuals' resilience to maintain their normal routines and fearful responses to the perceived threat of infection. Posted image descriptions revealed that people felt deprived of contact with nature and other human beings. Concerns over child-rearing and education were also a dominant theme.

To continue their normal lives through COVID-19, people utilized various self-care strategies to protect themselves from infection, maintain their physical health, and keep their psychological stability. These included adhering to safety measures, doing daily workouts, and having family quality time (e.g., visiting an exhibition, walking with pets). It is noteworthy that despite the crisis of the pandemic, tokens expressing positive emotions (happiness, love, healing, gratitude) appeared in high frequency in the posts. The frequent occurrences of positive emotional expressions could be due to several reasons. One could be that May, the time-point of the current study's data collection, is a "family month" in Korea when people express gratitude and love for their families. In addition, the implementation of sustained social-distancing measures could have helped people regain a sense of control, leading them to express gratitude for the governments' support and medical staff's dedication. Given that SNS platforms tend to be used to emphasize the positive aspects of life (Alhabash and Ma, 2017), Instagram users might have shared the emotions that they appraised as more positive. Regardless of the reasons, it is possible that expressing positive emotions helped regulate their emotions better (Burns et al., 2008). Given that positive emotions increase physical health and immunity (Cohen et al., 2003) and improve problem-solving skills (Estrada et al., 1997), the circulation of positive emotional expressions through Instagram posts possibly contributed to the development of optimism to overcome the COVID-19 crisis.
On the flip side of individual resilience in daily life management and emotional regulation, constant struggles with fear and anxiety over the perceived threat of infection emerged as a prominent theme. The fear of COVID-19 re-proliferation was a major theme derived from both the co-word (Cluster 2) and topic modeling analyses (Theme 2). What needs attention is that people's fear could turn into blame and hatred for a particular group of people. As manifested by the Itaewon nightclub case in this study, when people face a greater degree of threat than they had managed to cope with, they can respond in a way that creates social conflicts and publicizes prejudicial social attitudes against minority groups, as also noticed in other studies (Darling-Hammond et al., 2020; Roberto et al., 2020). It is noteworthy that despite the fact that there were other infection cases reported within the data collection period, only the worries about COVID19 spread in connection with gay clubs were a dominant theme detected by the co-word analysis. Many of the Instagram posts blatantly criticized the LGBTQ community ("sexual minorities") for being responsible for the massive infection. Their message could be phrased as follows: Their misbehaviors caused the virus spread; as they are a threat to the community, they should bear social hatred. Intolerance and othering of LGBTQ people, which has been a dominant view in South Korea (Kim, 2004; Rich and Eliassen, 2019), seemed affirmed as legitimate in the war against the pandemic. Yet, dynamics of resistance emerged through the Instagram posts. In response to the dominant message, some people raised awareness of the human rights of LGBTQ people while others reinterpreted the issue from a viewpoint of effectiveness for reducing the virus spread. This suggests that the discourse practices through Instagram posts involve power and resistance, as do the discourse practices in a physical offline space (Fairclough, 1995; Kress, 1990; Wodak, 2002).

This finding of our study could be aligned with Sohn (2020). Sohn (2020) showed how media discourse in South Korea contributed to shaping and reinforcing social fear and hatred in the era of COVID-19. In her linguistic analysis of news headlines related to COVID-19 on South Korean TV and newspapers, Sohn (2020) also pointed out that in May 2020, when the "nightclub" news came out, LGBTQ people were subjected to media violence. The news headlines often employed the metaphor of war (e.g., "corona battle," "warriors in white robes," "COVID-19 defense system faltered") and expressions otherizing specific regions (e.g., "Daegu-Corona") and population groups (e.g., "Shincheonji church as a coronavirus host", "Will Itaewon gay clubs become 


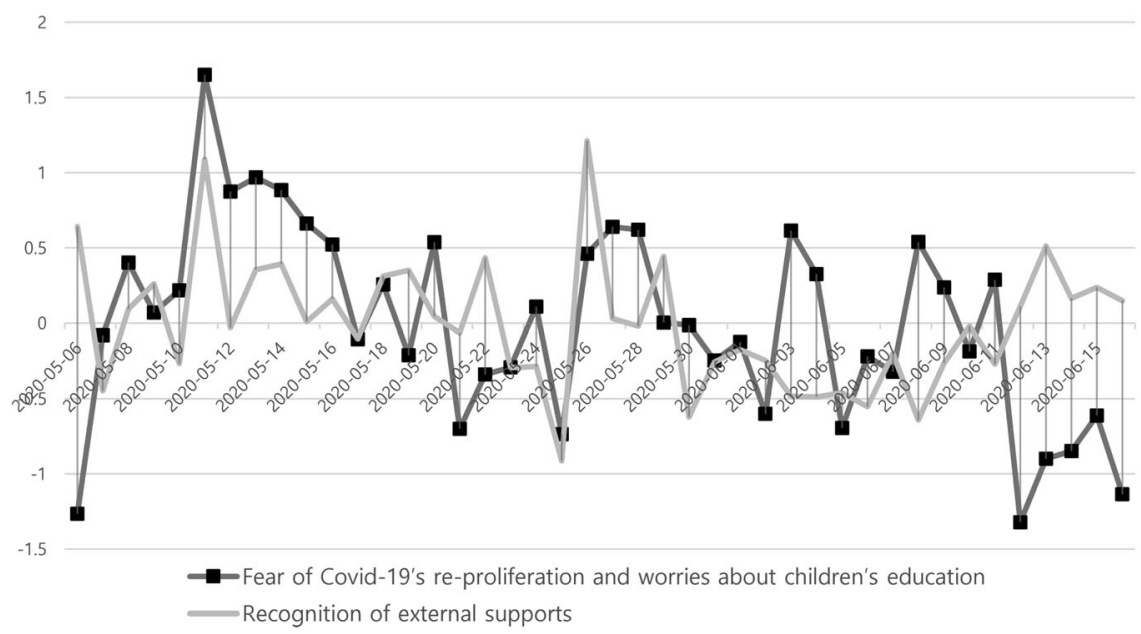

Fig. 4 Topic proportions of Fear of COVID-19 Re-Proliferation and Recognition of External Support. The $y$-axis indicates the average topic proportion estimates per theme, and the $x$-axis indicates the posted dates.

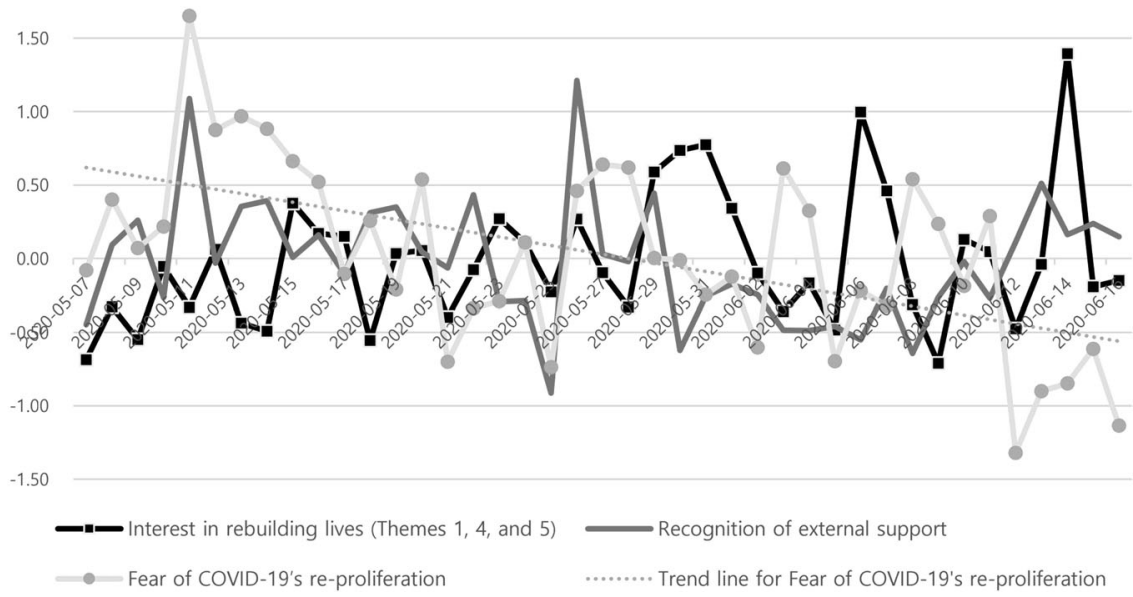

Fig. 5 Topic proportions of Interest in Rebuilding Lives and Recognition of External Support in comparison with Fear of COVID-19 Re-Proliferation. Interest in rebuilding lives shows the average proportions of Themes 1, 4, and 5. The $y$-axis indicates proportion estimates, and the $x$-axis indicates the posted dates.

another Shincheonji church?"). The "Shincheonji church" drew public attention as the first COVID-19 mass infection in Korea occurred at a church in Daegu. The church members were accused of bringing in the virus and even evading government epidemiological investigations. Social media highlighted that many Christian denominations had long been suspicious of Shincheonji's unorthodox doctrines and practices. Shincheonji soon became the target of public scorn and hatred. The headlines in Sohn's (2020) analysis were also indicative of the responsibility of Daegu, Shincheonji, and LGBTQ people in the COVID-19 spread.

This finding raises the need for some deliberate measures to resist hate frame and othering, as well as promote the concepts of inclusion, diversity, and community among the general public (Darling-Hammond et al., 2020). Public acknowledgment and encouragement of empathetic concerns for others and altruistic/ prosocial behaviors could help reduce hatred and between-group hostility (Aydinli-Karakulak et al., 2021; Hartman and Morse, 2015). In this vein, Freeman et al. (2015) suggest the possibility of using an SNS campaign to promote public health. An SNS hashtag campaign in South Korea that shared messages of appreciation for medical staff and public officials could be an example.
In addition, our data showed that there were various issues that caused fear and anxiety, other than the occurrence of large-scale confirmed cases. South Korean people were worried about childrearing burdens and the education gap caused by restrictions on school attendance (Lee, 2020a), worsening economic difficulties for small business owners (Kim, 2020a), and threats to the medical systems (Choi, 2020). The changes over time in topic proportion estimates of the major topics (Figs. 3, 4, 5) also suggest that as the pandemic prolongs, governmental intervention and support, which were effective during the initial stages, might no longer be sufficient to help people recuperate and rebuild their daily lives. As the pandemic lengthens in time, social disconnection would increase, crisis situations would become diverse, and thus new coping resources would be needed for people to regulate their emotions and lives. This corroborates previous empirical findings on the impact of a social crisis. A new infectious disease involves a wide range of complex psychosocial effects (Cheung, 2004), causing more severe, widespread, and less manageable pain (Lee-Baggley et al., 2004; Maunder et al., 2006). This also resonates with the report that in the aftermath of the 2013-2016 Ebola outbreak, people showed a cyclical pattern of fear with a loss of trust in the health care system (Heymann et al., 2015; van Bortel et al., 2016). Ebola's long-standing, multi-layered 
psychological repercussions suggest that government and community support should meet the long-term, multi-layered psychological needs of individuals in order to prevent a significant decline in quality of life and economic productivity. A large-scale psychological quarantine system may include an increased number of mental health centers, online and visiting counseling services, and various community-based counseling programs (Jeon and Lee, 2020).

In our study, the number of Instagram posts was found to increase when people perceived a greater degree of threat, with the occurrence of large-scale confirmed cases. This indicates that Korean people rely upon SNS platforms such as Instagram to share and regulate their stressful feelings, corroborating recent reports on the surge of SNS usage during the pandemic (Annapurani, 2020; Williamson, 2020). Recent studies suggest that social sharing of emotion could achieve a constructive outcome when one positively reappraises a stressful event with assistance from others (see Rimé et al., 2020). This again emphasizes the importance of our collaborative effort to promote positive reappraisal of a stressful event in the community, by acknowledging empathetic concerns for others and altruistic/ prosocial behaviors. Caution should be exerted, however, in that sharing emotions through SNS does not always lead to a positive reappraisal. The nightclub case in our study alerts us to the possibility that sharing emotions through SNS rather reinforces the existing hatred against minorities and frames otherizing COVID-19 patients as if it were an act of protecting the community (Ziems et al., 2020; Harris, 2020). Further research is needed to suggest practical ways to reduce hatred and stigmatizing language use on SNS.

The limitations of the study should be noted. Even though Instagram has become one of the most popular SNS platforms among South Koreans (Kim, 2019), our analyses may not show the whole picture of how South Koreans experienced COVID-19 and social distancing, as there are populations who do not get access to Instagram conversations (e.g., the elderly). In addition, there could be some other posts written about COVID-19 and social distancing that our data failed to include because they did not use the hashtag "\#social_distancing" or “\#everyday_distancing". The analysis of SNS data, in nature, has a limitation that public perceptions and attitudes can only be inferred in reference to a specific time-point and event. If future research corroborates SNS data with other qualitative data including participants' own voices accounting for their emotions, thoughts, and behaviors in relation to an event being studied, it could interpret the discursive practices of people in social crisis more precisely. An investigation with a narrower focus on specific population groups' discursive practices (e.g., medical workers, working mothers, students, etc.) would provide useful information regarding support more tailored to a given population group. In addition, cultural differences in public responses and coping strategies to the COVID-19 pandemic would be worthy of investigation.

\section{Conclusion}

The current study analyzes a corpus of SNS data to describe how South Koreans managed the impacts of the COVID-19 pandemic in their daily lives. Our results shed light on individual resilience to maintain daily routines (or negotiate the change) through sharing stressful events and feelings on an SNS platform. However, as the perceived threat of the pandemic increases in magnitude and time length, individual resilience alone is not enough to make their daily lives sustainable and maintain community solidarity. Our results show that when the perceived threat and stress of infection increases, people would possibly seek out the persons or groups responsible for the unfavorable situation, and there is a high chance that specific social minority groups of the society become the target of blame. Individuals' discursive practices through SNS can reproduce discriminative viewpoints and even reinforce the hatred toward social minorities by framing it as legitimate. To help individuals and communities be sustainable during continuous social distancing, deliberate social measures should be taken to promote the concepts of inclusion, diversity, and community and resist the development of discrimination and hatred for specific groups, along with a long-term psychological quarantine system.

\section{Data availability}

Raw data (the text corpus retrieved from Instagram) collected and analyzed in the current study is in Korean language and available from the first author on reasonable request by emailing: kimalexis1129@gmail.com

Received: 24 August 2021; Accepted: 14 February 2022; Published online: 08 March 2022

\section{References}

Alhabash S, Ma M (2017) A tale of four platforms: motivations and uses of Facebook, Twitter, Instagram, and Snapchat among college students? Soc Media Soc 3:1-13. https://doi.org/10.1177/2056305117691544

Annapurani V (2020) Coronavirus impact: Social networking platforms see a surge in usage. Available via Info-tech. https://www.thehindubusinessline.com/ info-tech/coronavirus-impact-social-networking-platforms-see-a-surge-inusage/article31328658.ece. Accessed 12 May 2020

Aydinli-Karakulak A, Tepe B, Nurcan E et al. (2021) How prosocial behavior turns bad into good: an examination among Turkish-Bulgarian adolescents. Curr Psychol 40:3986-3996

Bae JH, Son JE, Song M (2013) Analysis of twitter for 2012 South Korea presidential election by text mining techniques. J Intell Inf Syst 19:141-156

Bisson JI, Roberts N, Macho GS (2003) Service innovations: The Cardiff traumatic stress initiative: an evidence-based approach to early psychological intervention following traumatic events. Psychiatr Bull 27:145-147

Blei DM, Ng AY, Jordan MI (2003) Latent dirichlet allocation. J Mach Learn Res 3:993-1022

Blommaert J, Maly I (2019) Invisible lines in the online-offline linguistic landscape. Tilburg Papers in Culture Studies 223. https://pure.uvt.nl/ws/portalfiles/ portal/29324025/TPCS_223_Blommaert_Maly.pdf

Boulianne S (2015) Social media use and participation: A meta-analysis of current research. Information. Inf Commun Soc 18:524-538. https://doi.org/10.1080/ 1369118X.2015.1008542

Bouvier G, Machin D (2018) Critical discourse analysis and the challenges and opportunities of social media. Rev Commun 18:178-192. https://doi.org/ 10.1080/15358593.2018.1479881

Brown RC, Fischer T, Goldwich AD et al. (2018) \#cutting: Non-suicidal self-injury (NSSI) on Instagram. Psychol Med 48:337-346. https://doi.org/10.1017/ S0033291717001751

Bruns A (2012) How long is a tweet? Mapping dynamic conversation networks on Twitter using Gawk and Gephi. Inf Commun Soc 15:1323-1351. https:// doi.org/10.1080/1369118X.2011.635214

Burns AB, Brown JS, Sachs-Ericsson N et al. (2008) Upward spirals of positive emotion and coping: replication, extension, and initial exploration of neurochemical substrates. Pers Individ Dif 44:360-370. https://doi.org/10.1016/ j.paid.2007.08.015

Cheng C, Tang CSK (2004) The psychology behind the masks: Psychological responses to the severe acute respiratory syndrome outbreak in different regions. Asian J Soc Psychol 7:3-7. https://doi.org/10.1111/j.1467839X.2004.00130.x

Cheung FM (2004) Commentary: reintegrating psychology into an expanded biopsychosocial model of severe acute respiratory syndrome. Asian J Soc Psychol 7:83-88. https://doi.org/10.1111/j.1467-839X.2004.00136.x

Choi H (2020) Half of the COVID-19 health care and prevention staffs experience anxiety about within-workplace infection. Available via The Hankyoreh http://www.hani.co.kr/arti/society/health/948963.html. Accessed 12 May 2020

Cohen S, Doyle WJ, Turner RB et al. (2003) Emotional style and susceptibility to the common cold. Psychosom Med 65:652-657. https://doi.org/10.1097/ 01.PSY.0000077508.57784

Cover R (2012) Performing and undoing identity online: Social networking, identity theories and the incompatibility of online profiles and friendship regimes. Converg 18:177-193. https://doi.org/10.1177/1354856511433684 
Dam G, Kaufmann S (2008) Computer assessment of interview data using latent semantic analysis. Behav Res Methods 40:8-20. https://doi.org/10.3758/ BRM.40.1.8

Darling-Hammond S, Michaels EK, Allen AM et al. (2020) After "The China Virus” Went Viral: Racially Charged Coronavirus Coverage and Trends in Bias Against Asian Americans. Health Educ Behav. https://doi.org/10.1177/ 1090198120957949

de Souza Júnior J (2021) Transmediatisation of the Covid-19 crisis in Brazil: the emergence of (bio-/geo-) political repertoires of (re-)interpretation. Humanit soc sci 8:1-15. https://doi.org/10.1057/s41599-021-00883-X

Dehghan E, Bruns A, Mitchell P et al. (2020) Discourse-analytical studies on social media platforms: A data-driven mixed-methods approach. In: Lind RA (ed) Produsing theory in a digital world 3.0: the intersection of audiences and production in contemporary theory. Peter Lang Publishing, New York, NY, pp. 159-177

Dutt A (2015) Part of speech tags in text mining. Available via My thoughts \& learnings. https://edumine.wordpress.com/2015/09/14/part-of-speech-tagsin-text-mining/. Accessed 12 May 2020

Estrada CA, Isen AM, Young MJ (1997) Positive affect facilitates integration of information and decreases anchoring in reasoning among physicians. Organ Behav Hum Decis Process 72:117-135

Fairclough N (1995) Critical discourse analysis: The critical study of language. Longman, Longdra

Fairclough N, Wodak R (1997) Critical discourse analysis. In: van Dijk TA (ed) Discourse as social interaction, vol 2. Sage, CA, pp. 258-284

Feldman R, Dagan I (1995) Knowledge discovery in textual databases (KDT). KDT-knowledge discovery in texts. Paper presented at the 1st annual conference on knowledge discovery and data mining, Montreal, 20-21 August 1995

Freeman B, Potente S, Rock V et al. (2015) Social media campaigns that make a difference: what can public health learn from the corporate sector and other social change marketers. Public Health Res Pract. https://doi.org/10.17061/ phrp2521517

Gillmor D (2006) How to use Flickr: The digital photography revolution. Thomson Course Technology, Boston

Hale T, Angrist N, Kira B et al. (2020) Variation in government responses to Covid-19 Version 5.0. Dissertation, University of Oxford

Harris M (2020) Coronavirus fears have inspired shaming and death threats online. This is how public concern turns into harassment. Available via Insider. https:/www.insider.com/coronavirus-shaming-viral-callout-onlinepandemic-behavior-covid-2020-4. Accessed 22 May 2020

Hartman AC, Morse BS (2015) Wartime violence, empathy, and inter group altruism: Evidence from the Ivoirian refugee crisis in Liberia. Available via Semantic scholar. https://pdfs.semanticscholar.org/6585/ 759c3c88ccaef7c307fb221ed5bb82b1a4c2.pdf. Accessed 22 May 2020

Heymann DL, Chen L, Takemi K et al. (2015) Global health security: the wider lessons from the west African Ebola virus disease epidemic. Lancet 385:1884-1901. https://doi.org/10.1016/S0140-6736(15)60858-3

Janasik N, Honkela T, Bruun H (2009) Text mining in qualitative research: Application of an unsupervised learning method. Organ Res Methods 12:436-460. https://doi.org/10.1177/1094428108317202

Jang S (2020) No place to go on Children's Day... A different cultural landscape of the Family Month. Available via Kukmin Ilbo. http://news.kmib.co.kr/article/ view. asp arcid $=0014542707 \& \operatorname{code}=61121111 \& \mathrm{cp}=$ nv. Accessed 22 May 2020

Jeon J, Lee J (2020) Coronavirus Disease-19 current state of mental health care and tasks. Korea Institute for Health and Social Affairs 375:1-8

Kang A (2020) Twenty-seven newly diagnosed COVID-19 patients... decreased under 30 cases within five days. Available via Yonhap News. https:// www.yna.co.kr/view/AKR20200531016551530?input=1195m. Accessed 16 May 2020

Khosravinik M (2017) Social media critical discourse studies (SM-CDS). In: Flowerdew J, Richardson J (eds) Handbook of Critical Discourse Analysis. Routledge, London, pp. 582-596

Kim C (2019) Koreans use Instagram for communication, information searching, and shopping. Available via Asia Economics. http://view.asiae.co.kr/news/ view.htm?idxno=2019050717165993111. Accessed 23 May 2020

Kim H (2020a) Government and Cheongwadae call for 'COVID-19 public intervention' ... "an urgent intervention should be taken for the small business owners”. Available via Joongang Ilbo. https://news.joins.com/article/ 23777810. Accessed 23 May 2020

Kim SH (2004) Attitude and social distance towards the minority group in the Korean society. Soc Res 7:169-206

Kim Y (2020b) 'Itaewon Nightclub' COVID-19 infection spreads... An exhaustive inspection proceeds. Available via KBS News. http://news.kbs.co.kr/news/ view.do? ncd $=4442578 \& \mathrm{ref}=\mathrm{A}$. Accessed 23 May 2020

Korean Central Disease Control Headquarters (2020) Guidelines. Available via Korean Central Disease Control. http://ncov.mohw.go.kr/en/guidelineList.do?
brdId $=18 \&$ brdGubun $=181 \&$ dataGubun $=\&$ ncvContSeq $=\&$ contSeq $=\&$ boar d_id=\&gubun=. Accessed 2 May 2020

Kress G (1990) Critical discourse analysis. Annu Rev Appl Linguist 11:84-99

Lau JT, Griffiths S, Choi KC et al. (2010) Avoidance behaviors and negative psychological responses in the general population in the initial stage of the $\mathrm{H} 1 \mathrm{~N} 1$ pandemic in Hong Kong. BMC 10:1-13. https://doi.org/10.1186/1471-2334 10-139. Infect Dis

Lawler EE (2003) Reward practices and performance management system effectiveness. Organ Dyn 32:396-404

Lee C (2020) COVID-19 postponed school opening, conditions stay unchanged. Available via The Hankyoreh. http://www.hani.co.kr/arti/society/schooling/ 944492.html. Accessed 21 May 2020

Lee C (2020) The re-opening of public museums, galleries, libraries, etc. seems possible from tomorrow... Ministry of Culture, Sports and Tourism declared the re-opening from 22nd. Available via KBS News. http://news.kbs.co.kr/ news/view.do?ncd=4497446\&ref=A. Accessed 21 May 2020

Lee-Baggley D, DeLongis A, Voorhoeave P et al. (2004) Coping with the threat of severe acute respiratory syndrome: Role of threat appraisals and coping responses in health behaviors. Asian J Soc Psychol 7:9-23. https://doi.org/ 10.1111/j.1467-839X.2004.00131.x

Leech NL, Onwuegbuzie AJ (2008) Qualitative data analysis: A compendium of techniques and a framework for selection for school psychology research and beyond. Sch Psychol Q 23:587-604. https://doi.org/10.1037/1045-3830.23.4.587

Lepore SJ, Ragan JD, Jones S (2000) Talking facilitates cognitive-emotional processes of adaptation to an acute stressor. J Pers Soc Psychol 78:499-508 https://doi.org/10.1037/0022-3514.78.3.499

Maesse J (2020) "New normality": the political unconscious of corona discourse and global rearrangements. DiscourseNet Collaborative Work Paper Series 2:1-3

Main A, Zhou Q, Ma Y et al. (2011) Relations of SARS-related stressors and coping to Chinese college students' psychological adjustment during the 2003 Beijing SARS epidemic. J Couns Psychol 58:410-423. https://doi.org/10.1037/a0023632

Manning CD, Surdeanu M, Bauer J et al. (2014) The Stanford CoreNLP natural language processing toolkit. Paper presented at the 52nd annual meeting of the association for computational linguistics, Baltimore, 22-27 June 2014

Martin TW, Yoon D (2020) How South Korea Successfully Managed Coronavirus. Available via The Wall Street Journal. https://www.wsj.com/articles/lessons-fromsouth-korea-on-how-to-manage-covid-11601044329. Accessed 13 May 2020

Maunder RG, Lancee WJ, Balderson KE et al. (2006) Long-term psychological and occupational effects of providing hospital healthcare during SARS outbreak. Emerg Infect Dis 12:1924-1932. https://doi.org/10.3201/eid1212.060584

McCallum AK (2002) MALLET: a machine learning for language toolkit. Available via UMASS AMBERST. http://mallet.cs.umass.edu. Accessed 4 May 2020

Mihashi M, Otsubo Y, Yinjuan X et al. (2009) Predictive factors of psychological disorder development during recovery following SARS outbreak. Health Psychol 28:91-100. https://doi.org/10.1037/a0013674

Mimno D, McCallum A (2008) Topic models conditioned on arbitrary features with Dirichlet multinomial regression. Paper presented at the 24 th conference on uncertainty in artificial intelligence, Helsinki, Finland, 9-12 July 2008

Nabity-Grover T, Cheung CMK, Thatcher JB (2020) Inside out and outside in: How the COVID-19 pandemic affects self-disclosure on social media. Int J Inf Manage. https://doi.org/10.1016/j.ijinfomgt.2020.102188

Nam Y (2020) Highschool seniors will begin going school from 11th... Reasons why middle school seniors were excluded. Available via Joongang Ilbo. https://news.joins.com/article/23767384. Accessed 16 May 2020

Nils F, Rimé B (2012) Beyond the myth of venting: Social sharing modes determine the benefits of emotional disclosure. Eur J Soc Psychol 42:672-681. https:// doi.org/10.1002/ejsp.1880

Nolen-Hoeksema S, Davis CG (1999) "Thanks for sharing that": Ruminators and their social support networks. J Pers Soc Psychol 77:801-814

Oh SY (2020) South Korea's success against COVID-19. Available via The Regulatory Review. https://www.theregreview.org/2020/05/14/oh-south-koreasuccess-againstcovid-19/. Accessed 23 May 2020

Páez D, Basabe N, Ubillos S et al. (2007) Social sharing, participation in demonstrations, emotional climate, and coping with collective violence after the March 11th Madrid bombings. J Soc Issues 63:323-337

Ramalingaswami V (2001) Psychosocial effects of the 1994 plague outbreak in Surat, India. Mil Med 166:29-30. https://doi.org/10.1093/milmed/166.suppl_2.29

Rich TS, Eliassen I (2019) What's Behind South Korea's Persistent LGBT Intolerance?. The Diplomat. Available via https://thediplomat.com/2019/03/whatsbehind-south-koreas-persistent-lgbt-intolerance/. Accessed 10 Jan 2022

Rimé B (2007) The social sharing of emotion as an interface between individual and collective processes in the construction of emotional climates. J Soc Issues 63:307-322

Rimé B (2009) Emotion elicits the social sharing of emotion: Theory and empirical review. Emot Rev 1:60-85. https://doi.org/10.1177/1754073908097189

Rimé B, Bouchat P, Paquot L et al. (2020) Intrapersonal, interpersonal, and social outcomes of the social sharing of emotion. Curr Opin Psychol 31:127-134. https://doi.org/10.1016/j.copsyc.2019.08.024 
Rimé B, Finkenauer C, Luminet O et al. (1998) Social sharing of emotion: New evidence and new questions. Eur Rev Soc Psychol 9:145-189. https://doi.org/ 10.1080/14792779843000072

Roberto KJ, Johnson AF, Rauhaus BM (2020) Stigmatization and prejudice during the COVID-19 pandemic. Adm Theory Prax 42:364-378. https://doi.org/ $10.1080 / 10841806.2020 .1782128$

Serafini G, Parmigiani B, Amerio A et al. (2020) The psychological impact of COVID-19 on the mental health in the general population. Int J Med 113:531-537. https://doi.org/10.1093/qimed/hcaa201

Shim S, Choo I, Nam G et al. (2020) Seventy new COVID-19 cases, occurred in a delivery center this time. Available via Joongang Ilbo. https://news.joins.com/ article/23787485. Accessed 11 May 2020

Sohn D (2020) A study on the expressions used in COVID-19 news: Focusing on fear and hate reflected in headlines. Ehwa Lang Symp 51:137-166

Teso E, Olmedilla M, Martinez-Torres MR et al. (2018) Application of text mining techniques to the analysis of discourse in eWOM communication from a gender perspective. Technol Forecast Soc Change 129:131-142. https:// doi.org/10.1016/j.techfore.2017.12.018

van Bortel T, Basnayake A, Wurie F et al. (2016) Psychosocial effects of an Ebola outbreak at individual, community and international levels. Bull World Health Organ 94:210-214. https://doi.org/10.2471/BLT.15.158543

van Dijck J (2013) The culture of connectivity: A critical history of social media. OUP, Oxford

van Dijk TA (2008) Discourse and context: a socio-cognitive approach. Cambridge University Press, New York

Wiedemann G (2019) Text mining for discourse analysis: An exemplary study of the debate on minimum wages in Germany. In: Scholz R (ed.) Quantifying approaches to discourse for social scientists. Postdisciplinary studies in discourse. Palgrave Macmillan, Cham, https://doi.org/10.1007/978-3-31997370-8_7

Williamson DA (2020) US social media usage: How the coronavirus is changing consumer behavior. Available via eMarketer. https://www.emarketer.com/ content/us-social-media-usage. Accessed May 272020

Wodak R (2002) What CDA is about: A summary of its history, important concepts and its development. In: Wodak R, Meyer M (eds) Methods of critical discourse analysis. Sage, London, pp. 1-3

Wodak R (2008) Introduction. In: Wodak R, Kryzanowski M (eds) Qualitative discourse analysis in the social sciences. Palgrave Macmillan, Basingstoke

Ziems C, He B, Soni S (2020) Racism is a virus: Anti-asian hate and counterhate in social media during the covid-19 crisis. Available via Cornell University. https://arxiv.org/abs/2005.12423. Accessed 2 May 2020

\section{Acknowledgements}

This work was supported by Hankuk University of Foreign Studies Research Fund of 2021 .

\section{Competing interests}

The authors declare no competing interests.

\section{Ethical approval}

Ethical approval was not required for the present type of study that used voluntarily and openly shared online posts with no personally identifiable information.

\section{Informed consent}

This article does not contain any studies with human participants performed by any of the authors.

\section{Additional information}

Correspondence and requests for materials should be addressed to Hyun-Woo Lim.

Reprints and permission information is available at http://www.nature.com/reprints

Publisher's note Springer Nature remains neutral with regard to jurisdictional claims in published maps and institutional affiliations

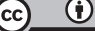

Open Access This article is licensed under a Creative Commons Attribution 4.0 International License, which permits use, sharing, adaptation, distribution and reproduction in any medium or format, as long as you give appropriate credit to the original author(s) and the source, provide a link to the Creative Commons license, and indicate if changes were made. The images or other third party material in this article are included in the article's Creative Commons license, unless indicated otherwise in a credit line to the material. If material is not included in the article's Creative Commons license and your intended use is not permitted by statutory regulation or exceeds the permitted use, you will need to obtain permission directly from the copyright holder. To view a copy of this license, visit http://creativecommons.org/ licenses/by/4.0/

(C) The Author(s) 2022 